\title{
Theoretical Analysis of NO Formation Near The Primary Reaction Zone in Methane Combustion
}

\author{
J. H. AY and M. SICHEL \\ Department of Aerospace Engineering, The University of Michigan, Ann Arbor, Michigan 48105
}

\begin{abstract}
The complete kinetics of the $\mathrm{CH}_{4}$-air reaction are used to study the details of NO formation near the primary reaction zone. The species and energy conservation equations are used in the analysis, however, diffusion and heat conduction within the reaction zone are neglected. The overshoot of the concentrations of the radicals $\mathrm{O}, \mathrm{OH}$, and $\mathrm{H}$ over their post flame equilibrium values appears to explain the phenomenon of "prompt NO" due to the very high NO formation rate near the flame for values of the equivalence ratio $\phi<1$. 1. The effects of flame parameters on this radical overshoot are investigated. In addition, the results of the equilibrium theory, which has been used by previous authors to compute NO formation, have been compared in the detailed kinetic calculations. Computations with and without $\mathrm{HO}_{2}$ reactions, which may influence NO production through their effect on radical recombination, were compared.
\end{abstract}

\section{Introduction}

The Zeldovitch Mechanism [1], consisting of the reactions

$$
\begin{aligned}
& \mathrm{O}+\mathrm{N}_{2} \rightleftharpoons \mathrm{NO}+\mathrm{N}, \\
& \mathrm{N}+\mathrm{O}_{2} \rightleftharpoons \mathrm{NO}+\mathrm{O},
\end{aligned}
$$

supplemented by the additional reaction

$$
\mathrm{OH}+\mathrm{N} \rightleftharpoons \mathrm{NO}+\mathrm{H}
$$

in fuel rich flames has been generally employed to compute the formation of NO in combustion [2-15]. Since reaction (XIV) is much slower than the chain branching and recombination reactions in most flames, the above reactions have been used to model NO formation by taking the concentrations of $\mathrm{N}_{2}, \mathrm{O}_{2}, \mathrm{O}$, and, $\mathrm{OH}$ at the post flame equilibrium value and evaluating the rate constants at the adiabatic flàme temperature $[1,23-25]$. Any formation of NO within the flame is neglected so that the NO concentration immediately downstream of the flame is taken as zero in these calculations. Bowman [4] refers to this approach as the "Equilibrium Theory".

By extrapolating the measured NO concentra- tion profile downstream of a flat frame backward, Fenimore [16] found a finite value of the NO concentration at the flame front in contradiction to the assumption above. He referred to this NO concentration as "prompt NO". Prompt NO has also been observed by Bowman et al. [2-4] in shock induced combustion, and by Bachmaier [5], Iverach et al. [13], and Haynes et al. [27] in a variety of hydrocarbon flames.

The measurements of prompt NO suggest that NO must form at a very high rate in the primary reaction zone or immediately downstream of the flame. Fenimore [16] found that the Zeldovitch Mechanism, alone, did not provide reaction rates high enough to explain prompt NO. Bowman et al. [2-4] and Sarofim and Pohl [26] were able to explain the prompt NO observed in shock tubes and laminar flame experiments using the Zeldovitch Mechanism provided the overshoot of the concentrations of $\mathrm{O}, \mathrm{OH}$, and $\mathrm{H}$ above their post flame equilibrium values is taken into account in the region close to the main reaction zone or flame. This theory is sometimes called the "Radical Overshoot Theory".

The radical overshoot theory appears to agree with measurements for lean or nearly stoichiometric hydrocarbon flames, however, for rich 
flames the experimental results of Bachmaier et al. [5] and Iverach et al. [13], as well as Fenimore's results [16] indicate rates of NO formation much higher than those computed using the Zeldovitch Reactions even when the non-equilibrium free radical concentrations are taken into account. $A$ number of questions thus remain regarding the origin of prompt $\mathrm{NO}$ and the detailed kinetics close to the flame.

The radical overshoot theory requires a detailed consideration of flame kinetics, or the use of other suitable approximate methods to compute the non-equilibrium concentrations of $\mathrm{O}, \mathrm{OH}$, and $H$. With a few exceptions approximate methods have been used to estimate non-equilibrium free radical concentrations. Analytical studies of the detailed kinetics of $\mathrm{NO}$ formation in the shock induced combustion of $\mathrm{CH}_{4}$-air have been made by Bowman et al. [2] but were limited to isothermal reactions in shock tubes. Detailed kinetic calculations for the combustion of $\mathrm{CH}_{4}$-air mixtures in which temperature variations are taken in to account have been made by Marteney [17]. Marteney's study was limited to the range of equivalence ratio $0.8 \leq \phi \leq 1.25$ and used relatively high values for the initial reactant temperature ranging from $1000^{\circ} \mathrm{K}$ to $2000^{\circ} \mathrm{K}$. The kinetic scheme used by Marteney [17] included the Zeldovitch reactions XIV and XV, but omitted reaction XVI which has been found to be important in stoichiometric and fuel rich mixtures. Marteney [17] made no attempt to study the possible correlation of prompt NO to radical overshoots.

In order to clarify the relationship between prompt $\mathrm{NO}$ and overshoots in radical concentrations, detailed kinetic calculations of the combus. tion of methane in a nitrogen-oxygen mixture have been made and are described below. The details of formation of NO within and immediately downstream of the flame have been studied. The temperature variation within the reaction region is taken into account in the calculations, however, diffusion and heat conduction, which are important within laminar flames, are neglected. Nevertheless, it is felt that the results show the link between radical overshoot, flame temperature, and the NO formation rate. The species concen- tration profiles in the reaction zone of the flame are readily computed when transport effects are neglected, making it possible to study the influence of mixture ratio, fuel temperature, and pressure on NO formation.

The analytical model used in the computations is formulated in Section II, and the results of the analysis are presented in Section III.

\section{Formulation of the Analytical Model}

As indicated above, detailed consideration of flame kinetics is necessary to compute the nonequilibrium concentrations of the radicals $\mathrm{O}, \mathrm{H}$, and $\mathrm{OH}$ and the rate of $\mathrm{NO}$ formation within the combustion region. The fourteen species listed in Table 1 have been considered in the computations, and for convenience in computation the species conservation equations have been used in the form,

$$
\frac{d \tilde{Z}_{i}}{d t}=\frac{w_{i}}{\rho z_{i}}, i=1, \ldots, 14,
$$

where

$$
\begin{aligned}
z_{i}= & \left(Y_{i} / M_{i}\right)=\text { moles of species } i \text { per unit } \\
& \text { mass of mixture } \\
\rho= & \text { local density of the gas mixture } \\
\tilde{Z_{i}=} & \ln z_{i}=\ln \left(Y_{i} / M_{i}\right) \\
w_{i}= & \text { net rate of formation of species } i \text { in moles } \\
& \text { per unit volume per unit time } \\
Y_{i}= & \text { mass fraction of species } i \\
M_{i}= & \text { molecular weight of species } i
\end{aligned}
$$

The $\mathrm{CH}_{4}$-air kinetic scheme due to Bowman [2-4] as presented in Table 1 has been used to determine the reaction rates $w_{i}$ in Eq. (1) above. The kinetic scheme fails to include reactions involving $\mathrm{HO}_{2}$. Homer and Sutton [28] have suggested that $\mathrm{HO}_{2}$ may provide an important path for radical recombination, and the influence of $\mathrm{HO}_{2}$ will be considered below in a few cases.

The rates $w_{i}$ are now readily determined. For instance, for $\mathrm{CH}_{4}$, corresponding to $i=1$,

$$
\begin{aligned}
w_{1}= & -\left(\rho^{3} / M\right)\left[k_{1 f}\left(z_{1} / \rho\right)-k_{1 b} z_{2} z_{5}\right] \\
& -\rho^{2}\left[k_{2 f} z_{1} z_{8}-k_{2 b} z_{2} z_{7}\right]
\end{aligned}
$$


TABLE 1

Kinetic Scheme of $\mathrm{CH}_{4}$-Air Combustion Due to Bowman [2-4]

\begin{tabular}{cccccc}
\hline $\begin{array}{c}\text { Chemical species Considered } \\
\text { S }\end{array}$ & & & & \\
& Species & $i$ & Species & $i$ & Species \\
\hline 1 & $\mathrm{CH}_{4}$ & 5 & $\mathrm{H}$ & 10 & $\mathrm{NO}$ \\
2 & $\mathrm{CH}_{3}$ & 6 & $\mathrm{O}$ & 11 & $\mathrm{CO}_{2}$ \\
3 & $\mathrm{CHO}$ & 7 & $\mathrm{H}_{2} \mathrm{O}$ & 12 & $\mathrm{O}_{2}$ \\
4 & $\mathrm{CO}$ & 8 & $\mathrm{OH}$ & 13 & $\mathrm{H}_{2}$ \\
\end{tabular}

Kinetic scheme

\begin{tabular}{|c|c|c|c|c|c|c|c|c|c|c|c|c|c|c|c|c|c|}
\hline$j$ & & & & Rea & & & & $j$ & & & & & Reacti & & & & \\
\hline 1 & $\mathrm{CH}_{4}$ & + & M & $\rightleftharpoons$ & $\mathrm{CH}_{3}$ & $+\mathrm{H}+$ & M & 11 & & & 0 & + & $\mathrm{H}_{2}$ & $\rightleftharpoons$ & $\mathrm{OH}$ & + & $\mathrm{H}$ \\
\hline 2 & $\mathrm{CH}_{4}$ & + & $\mathrm{OH}$ & $\rightleftharpoons$ & $\mathrm{CH}_{3}$ & $+\mathrm{H}_{2} \mathrm{O}$ & & 12 & & & $\mathrm{O}$ & + & $\mathrm{H}_{2} \mathrm{O}$ & $\rightleftharpoons$ & $\mathrm{OH}$ & + & $\mathrm{OH}$ \\
\hline 3 & $\mathrm{CH}_{4}$ & + & $\mathrm{O}$ & $\rightleftharpoons$ & $\mathrm{CH}_{3}$ & $+\mathrm{OH}$ & & 13 & & & $\mathrm{H}$ & + & $\mathrm{H}_{2} \mathrm{O}$ & $\rightleftharpoons$ & $\mathrm{H}_{2}$ & + & $\mathrm{OH}$ \\
\hline 4 & $\mathrm{CH}_{4}$ & + & $\mathrm{H}$ & $\rightleftharpoons$ & $\mathrm{CH}_{3}$ & $+\mathrm{H}_{2}$ & & 14 & & & 0 & + & $\mathrm{N}_{2}$ & $\rightleftharpoons$ & NO & + & $\mathrm{N}$ \\
\hline 5 & $\mathrm{CH}_{3}$ & + & $\mathrm{O}_{2}$ & $\rightleftharpoons$ & $\mathrm{CHO}$ & $+\mathrm{H}_{2} \mathrm{O}$ & & 15 & & & $\mathrm{~N}$ & + & $\mathrm{O}_{2}$ & $\rightleftharpoons$ & NO & + & $\mathrm{O}$ \\
\hline 6 & $\mathrm{CH}_{3}$ & + & $\mathrm{O}$ & $\rightleftharpoons$ & $\mathrm{CHO}$ & $+\mathrm{H}_{2}$ & & 16 & & & $\mathrm{OH}$ & + & $\mathrm{N}$ & $\rightleftharpoons$ & NO & + & $\mathbf{H}$ \\
\hline 7 & $\mathrm{CHO}$ & + & $\mathrm{OH}$ & $\rightleftharpoons$ & $\mathrm{CO}$ & $+\mathrm{H}_{2} \mathrm{O}$ & & 17 & $\mathrm{H}$ & + & $\mathrm{OH}$ & + & $\mathbf{M}$ & $\rightleftharpoons$ & $\mathrm{H}_{2} \mathrm{O}$ & + & $M$ \\
\hline 8 & $\mathrm{CHO}$ & + & $\mathrm{M}$ & $\rightleftharpoons$ & $\mathrm{CO}$ & $+\mathrm{H}+$ & M & 18 & $\mathrm{H}$ & + & $\mathrm{H}$ & + & $\mathbf{M}$ & $\Rightarrow$ & $\mathrm{H}_{2}$ & + & M \\
\hline 9 & $\mathrm{CO}$ & + & $\mathrm{OH}$ & $\rightleftharpoons$ & $\mathrm{CO}_{2}$ & $+\mathrm{H}$ & & 19 & $\mathrm{O}$ & + & $\mathrm{O}$ & + & M & $\rightleftharpoons$ & $\mathrm{O}_{2}$ & + & M \\
\hline 10 & $\mathrm{H}$ & + & $\mathrm{O}_{2}$ & $\rightleftharpoons$ & o & $+\mathrm{OH}$ & & 20 & 0 & + & $\mathrm{H}$ & + & M & $\rightleftharpoons$ & $\mathrm{OH}$ & + & $\mathrm{M}$ \\
\hline
\end{tabular}

$$
\begin{gathered}
-\rho^{2}\left[k_{3 f} z_{1} z_{6}-k_{3 b} z_{2} z_{8}\right]-\rho^{2}\left[k_{4 f} z_{1} z_{5}\right. \\
\left.-k_{4 b} z_{2} z_{13}\right]
\end{gathered}
$$

$\frac{d}{d t}\left(\sum_{i} z_{i} H_{i}\right)=\frac{d T}{d t} \sum_{i} z_{i} \frac{d H_{i}}{d T}+\frac{1}{\rho} \sum_{i} H_{i} w_{i}=0$,

Similar expressions can be written for the other species and have been tabulated by Ay [23]. The total concentration of all species has been used whenever third body collisions occur.

The forward rate constants of the reactions in Table 1 were taken from Bowman, and are listed in Table 2. The reverse rate constants were evaluated from the forward rate constants and the equilibrium constants, taken from the JANAF Tables [18], and listed in Table 3.

Only combustion processes in which the kinetic energy of the flow is small compared to the thermal energy are considered. In the absence of transport effects, the energy equation then reduces to the statement that the specific enthalpy remains constant. In differential form the energy equation then becomes

where

$$
H_{i}=\text { molar enthalpy of species } i \text {. }
$$

The enthalpy $H_{i}$ has been computed using the polynomial

$$
\begin{aligned}
\frac{H_{i}}{R T}=A_{i 1} & +A_{i 2} \frac{T}{2}+A_{i 3} \frac{T^{2}}{3}+A_{i 4} \frac{T^{3}}{4} \\
& +A_{i 5} \frac{T^{4}}{5}+\frac{A_{i 6}}{T},
\end{aligned}
$$

where

$$
R=\text { the universal gas constant. }
$$


TABLE 2

Forward Rate Constant of $\mathrm{CH}_{4} / \mathrm{O}_{2} / \mathrm{N}_{2}$ System

\begin{tabular}{|c|c|c|c|c|c|c|}
\hline \multirow[b]{2}{*}{$\begin{array}{c}(j) \\
\text { Reaction }\end{array}$} & \multicolumn{5}{|c|}{$k_{j f}=A_{j} T^{B_{j}} e^{-E_{j} / T}\left(\mathrm{~cm}^{3} / \mathrm{mole} / \mathrm{sec}\right)$} & \multirow[b]{2}{*}{ Reference } \\
\hline & & $A_{j}$ & $B_{j}$ & & $E_{j}$ & \\
\hline 1 & 0.1 & $\times 10^{19}$ & 0 & 0.445 & $\times 10^{5}$ & 3 \\
\hline 2 & 0.28 & $\times 10^{14}$ & 0 & 0.25 & $\times 10^{4}$ & 2 \\
\hline 3 & 0.2 & $\times 10^{14}$ & 0 & 0.464 & $\times 10^{4}$ & 2 \\
\hline 4 & 0.69 & $\times 10^{14}$ & 0 & 0.595 & $\times 10^{4}$ & 2 \\
\hline 5 & 0.2 & $\times 10^{11}$ & 0 & & 0 & 2 \\
\hline 6 & 0.1 & $\times 10^{15}$ & 0 & & 0 & 2 \\
\hline 7 & 0.1 & $\times 10^{15}$ & 0 & & 0 & 2 \\
\hline 8 & 0.2 & $\times 10^{13}$ & 0.5 & 0.144 & $\times 10^{5}$ & 2 \\
\hline 9 & 0.56 & $\times 10^{12}$ & 0 & 0.545 & $\times 10^{3}$ & 2 \\
\hline 10 & 0.22 & $\times 10^{15}$ & 0 & 0.834 & $\times 10^{4}$ & 2 \\
\hline 11 & 0.17 & $\times 10^{14}$ & 0 & 0.475 & $\times 10^{4}$ & 2 \\
\hline 12 & 0.58 & $\times 10^{14}$ & 0 & 0.907 & $\times 10^{4}$ & 2 \\
\hline 13 & 0.84 & $\times 10^{14}$ & 0 & 0.101 & $\times 10^{5}$ & 2 \\
\hline 14 & 0.14 & $\times 10^{15}$ & 0 & 0.379 & $\times 10^{5}$ & 4 \\
\hline 15 & 0.64 & $\times 10^{10}$ & 1.0 & 0.314 & $\times 10^{4}$ & 4 \\
\hline 16 & 0.4 & $\times 10^{14}$ & 0 & & 0 & 4 \\
\hline 17 & 0.4 & $\times 10^{20}$ & -1.0 & & 0 & 4 \\
\hline 18 & 0.15 & $\times 10^{19}$ & -1.0 & & 0 & 4 \\
\hline 19 & 0.4 & $\times 10^{18}$ & -1.0 & & 0 & 4 \\
\hline 20 & 0.53 & $\times 10^{16}$ & 0 & 0.278 & $\times 10^{4}$ & 32 \\
\hline
\end{tabular}

The coefficients in (4) are taken from Gordon and McBride [19], and the resultant enthalpy values are then identical to those listed in the JANAF tables [18]. The reacting mixture is assumed to satisfy the perfect gas equation of state. In laminar flames or other low speed combustion processes such as considered here, the pressure $p$ is essentially constant.

The above equations are sufficient to determine the variation of the $z_{i}$ and the temperature $T$ once initial values are specified. The mole fractions of the species present can then be determined from

$$
X_{i}=z_{i}\left(\sum_{i} z_{i}\right)^{-1} .
$$

Conservation of the elements carbon, oxygen, hydrogen, and nitrogen, requires that the following relations among the $z_{i}$ 's be satisfied

$$
\begin{gathered}
z_{1}+z_{2}+z_{3}+z_{4}+z_{11}=m_{C} \\
z_{3}+z_{4}+z_{6}+z_{7}+z_{8}+z_{10}+2 z_{11}+2 z_{12}=m_{O}
\end{gathered}
$$

$$
\begin{gathered}
4 z_{1}+3 z_{2}+z_{3}+z_{5}+2 z_{7}+z_{8}+2 z_{13}=m_{H} \\
z_{9}+z_{10}+2 z_{14}=m_{N}
\end{gathered}
$$

The constants $m_{C}, m_{O}, m_{H}$, and $m_{N}$ are the 
TABLE 3

Equilibrium Constants ${ }^{a}$ of a $\mathrm{CH}_{4}-\mathrm{O}_{2}-\mathrm{N}_{2}$ System

\begin{tabular}{|c|c|c|c|c|c|c|}
\hline \multirow{3}{*}{$\begin{array}{c}\begin{array}{c}(j) \\
\text { Reaction }\end{array} \\
1\end{array}$} & \multicolumn{6}{|c|}{$K_{j}=a_{j} T^{b_{j}}{ }_{e}^{-e_{j} / T}$} \\
\hline & \multicolumn{2}{|r|}{$a_{j}$} & \multicolumn{2}{|c|}{$b_{j}$} & \multicolumn{2}{|c|}{$e_{j}$} \\
\hline & 0.64066 & $\times 10^{3}$ & -0.22325 & & 0.51693 & $\times 10^{5}$ \\
\hline 2 & 0.24525 & $\times 10^{2}$ & -0.17560 & & -0.83933 & $\times 10^{4}$ \\
\hline 3 & 0.11515 & $\times 10^{4}$ & -0.35911 & & 0.36842 & $\times 10^{3}$ \\
\hline 4 & 0.82512 & $\times 10^{3}$ & -0.41922 & & -0.51805 & $\times 10^{3}$ \\
\hline 5 & 0.51761 & $\times 10^{4}$ & -0.90331 & & -0.46072 & $\times 10^{5}$ \\
\hline 6 & 0.33278 & $\times 10^{3}$ & -0.70715 & & -0.46896 & $\times 10^{5}$ \\
\hline 7 & 0.44899 & & -0.28634 & & -0.45561 & $\times 10^{5}$ \\
\hline 8 & 0.11729 & $\times 10^{2}$ & -0.33396 & & 0.14526 & $\times 10^{5}$ \\
\hline 9 & 0.14276 & $\times 10^{-6}$ & 0.13083 & $\times 10$ & -0.13153 & $\times 10^{5}$ \\
\hline 10 & 0.52329 & $\times 10^{3}$ & -0.43979 & & 0.87000 & $\times 10^{4}$ \\
\hline 11 & 0.13955 & $\times 10$ & 0.60115 & $\times 10^{-1}$ & 0.88647 & $\times 10^{3}$ \\
\hline 12 & 0.46949 & $\times 10^{2}$ & -0.18351 & & 0.87618 & $\times 10^{4}$ \\
\hline 13 & 0.33643 & $\times 10^{2}$ & -0.24362 & & 0.78753 & $\times 10^{4}$ \\
\hline 14 & 0.16629 & $\times 10$ & 0.11865 & & 0.37671 & $\times 10^{5}$ \\
\hline 15 & 0.11427 & $\times 10^{2}$ & -0.10599 & & -0.15935 & $\times 10^{5}$ \\
\hline 16 & 0.21837 & $\times 10^{-1}$ & 0.33380 & & -0.24635 & $\times 10^{5}$ \\
\hline 17 & 0.38282 & $\times 10^{-1}$ & 0.47647 & $\times 10^{-1}$ & -0.60087 & $\times 10^{5}$ \\
\hline 18 & 0.12879 & $\times 10$ & -0.19600 & & -0.52211 & $\times 10^{5}$ \\
\hline 19 & 0.34346 & $\times 10^{-2}$ & 0.30393 & & -0.60025 & $\times 10^{5}$ \\
\hline 20 & 0.17973 & $\times 10$ & -0.13586 & & -0.51325 & $\times 10^{5}$ \\
\hline
\end{tabular}

${ }^{a}$ Units; calories, mole, cm, ${ }^{\circ} \mathrm{K}$, sec.

moles of carbon, oxygen, hydrogen, and nitrogen per unit mass of fuel-oxidizer mixture and will depend on the initial mixture ratio. The numerical computations have been simplified by replacing four of the differential equations (1) with the much simpler algebraic relations (6)-(9).

In a steady one-dimensional flow, the Lagrangian derivatives in Eqs. (1) and (3) can be related to the spatial derivatives of $z_{i}$ and $T$ by

$$
\frac{d z_{i}}{d t}=v \frac{d z_{i}}{d x}, \frac{d T}{d t}=v \frac{d T}{d x} .
$$

From the conservation of mass it follows that the fluid velocity $v$ will be given by

$$
\nu=\left(\rho_{o} v_{o}\right) / \rho .
$$

Because of the order of magnitude variations in the reaction rates, equations such as the system (1), which are then called stiff equations, demand special treatment. Numerical methods have recently been developed to deal with such equations [20-22]. The algorithm STIFF3, developed by Bowen [20], was used in the present calculations. 
A detailed program listing of the above kinetic calculations has been presented by Ay [23] .

\section{Calculated Results and Discussion}

The present analysis follows the chemical history of a fluid particle so that the calculated results are in the form of temperature-time and concentration-time profiles. For a particle moving through a laminar flame or other combustion region the position $x$ of the particle and the time are related by

$$
\frac{d x}{d t}=v=\frac{\rho_{o} \nu_{o}}{\rho}
$$

Actually, it might be more appropriate to refer to the time $t$ as the residence time of the particle in the combustion zone. Since the density varies through the flame the concentration distance profiles will differ from the concentration-time profiles. However, NO formation occurs mainly after the completion of the combustion reactions where the density has essentially reached its final value. In this portion of the combustion zone, which is of the greatest interest here, the time and distance profiles will be almost identical. In discussing the concentration and temperature profiles, it is clear that the term downstream is synonymous with increasing time.

Calculations have been made for mixtures of methane-oxygen-nitrogen with initial reactant temperatures, $T_{\text {reactant }}=500,1000$, and 1500

${ }^{\circ} \mathrm{K}$ at pressures of $1,5,10$, and $30 \mathrm{~atm}$, and for equivalence rations in the range $0.4 \leq \phi \leq 1.6$. The ratio of $\mathrm{N}_{2} / \mathrm{O}_{2}$ used in the present calculations is 3.32 , by volume. This value is very close to the $\mathrm{N}_{2} / \mathrm{O}_{2}$ ratio of 3.72 for air, and the adiabatic combustion temperatures of the two mixtures differ by at most $100^{\circ} \mathrm{K}$. The results of the present calculations will therefore be qualitatively similar to those which would be obtained for methane-air mixtures. In the numerical scheme used here it has been found that $T_{\text {reactant }}$ must be $500^{\circ} \mathrm{K}$ or more to initiate the combustion reactions.

Typical temperature and concentration profiles are shown in Fig. 1 for a $\mathrm{CH}_{4}$-air mixture at a
$T_{\text {reactant }}=1000^{\circ} \mathrm{K}$, and an equivalence ratio $\phi=1.0$, and exhibit four distinct regions which can be identified as an induction, a reaction, a radical recombination, and a post reaction zone. Reactions proceed isothermally in the induction zone where the initial formation of free radicals occurs. $\mathrm{CH}_{4}$ and $\mathrm{O}_{2}$ are consumed in the reaction zone, while the temperature begins to increase. The concentrations of $\mathrm{CO}$ and the free radicals increase to a peak value in excess of the downstream equilibrium value because of the inbalance between the fast chain branching reactions (X), (XI), and (XII) and the slower three body recombination reactions (XVII) - (XX). In the radical recombination region, the nonequilibrium concentrations of $\mathrm{CO}, \mathrm{O}, \mathrm{H}$, and $\mathrm{OH}$ relax to their flame equilibrium values, while the heat release from the recombination reactions drives the temperature to its final post flame value. Nitric oxide is formed mainly in the radical recombination and post reaction regions since the Zeldovitch reactions, (XIV) - (XVI), are much slower than the other combustion reactions.

Detailed radical and NO concentration profiles in the radical recombination and post flame region with $p=1 \mathrm{~atm}, T_{\text {react }}=500^{\circ} \mathrm{K}$, and $\phi=0.6$ are shown in Fig. 2, while NO concentrations for $\phi=$ $0.6,1.0$, and 1.4 are shown in Fig. 3. The peak of the $O$ concentration profile has been chosen as the point where time $t=0$ in these figures. For the lean mixture, shown in Fig. 2, with $\phi=0.6$, as well as for the rich mixture with $\phi=1.4$. The maximum NO formation rate occurs at or slightly downstream of the peak in $\mathrm{O}$ concentration, and then decreases throughout the post reaction region. This drop in the NO formation rate must be due to the decay of the concentrations of the $\mathrm{O}, \mathrm{OH}$, and $\mathrm{H}$ radicals in the recombination region since these are the only species directly involved in the NO formation reactions. In the stoichiometric mixture, on the other hand, it can be seen from Fig. 3 that the NO formation rate increases initially but then decreases. This initial increase is caused by the temperature rise due to radical recombination, and the fact that the radical concentration over shoot is relatively small and so has little influence on the NO formation rate. 


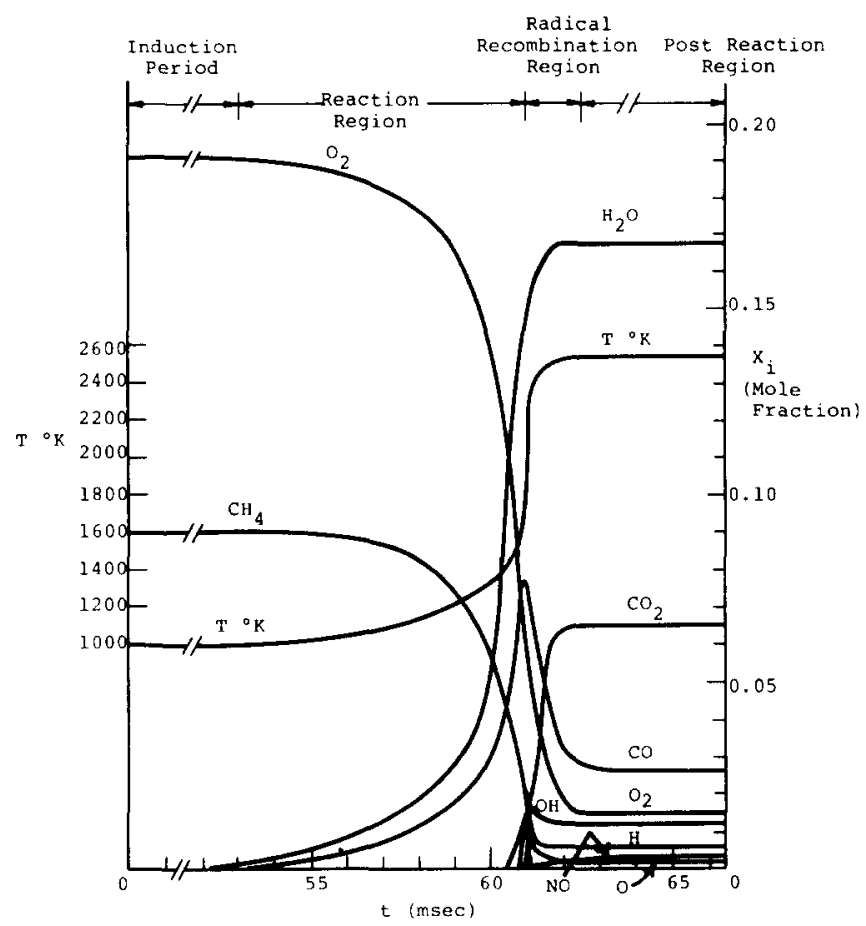

Fig. 1. Concentration and Temperature Profiles of a $\mathrm{CH}_{4} / \mathrm{O}_{2} / \mathrm{N}_{2}$ Mixture at $p=1 \mathrm{~atm}$ and $\phi=1.0\left(\mathrm{~N}_{2} / \mathrm{O}_{2}=3.32\right)$.

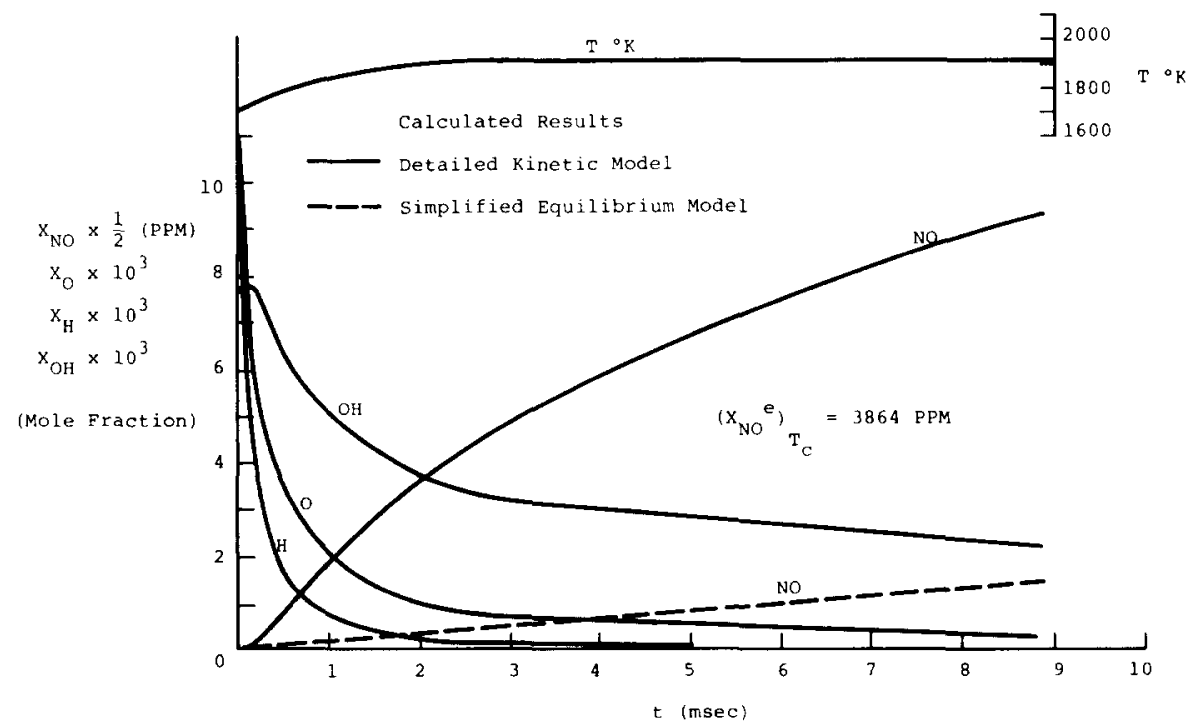

Fig. 2. Temperature and (NO, O, $\mathrm{H}$, and $\mathrm{OH}$ ) Concentration Profiles of a $\mathrm{CH}_{4} / \mathrm{O}_{2} / \mathrm{N}_{2}$ Mixture at $p=1 \mathrm{~atm}, T_{\text {react }}=500^{\circ} \mathrm{K}$, and $\phi=0.6\left(\mathrm{~N}_{2} / \mathrm{O}_{2}=3.32\right)$. 


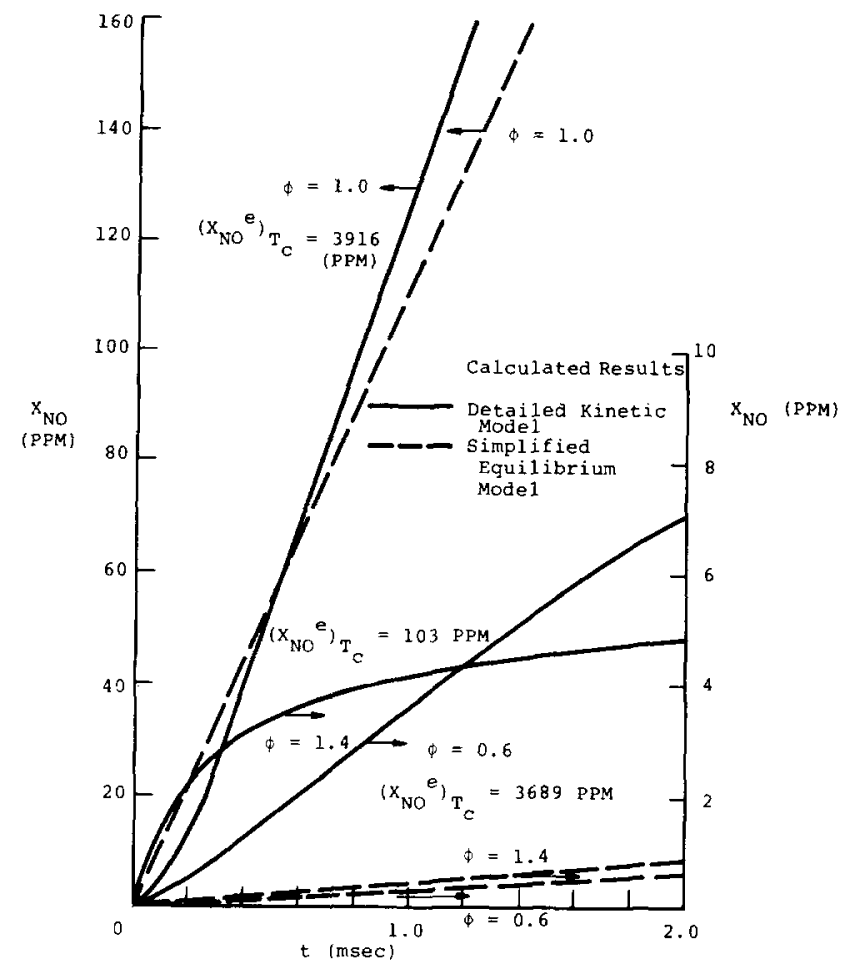

Fig. 3. Calculated NO Concentration Profiles of $\mathrm{CH}_{4} / \mathrm{O}_{2} / \mathrm{N}_{2} \mathrm{Mix}$ tures $\left(\mathrm{N}_{2} / \mathrm{O}_{2}=3.32\right)$ at $p=1 \mathrm{~atm}, T_{\text {react }}=500^{\circ} \mathrm{K}$, and $\phi=0.6$, 1.0 , and 1.4 .

The post flame variation of NO concentration has also been computed using reactions (XIV), $(\mathrm{XV})$, and (XVI) and the equilibrium values of the concentrations of $\mathrm{N}_{2}, \mathrm{O}_{2}, \mathrm{O}$ and $\mathrm{OH}$ as described in detail by Ay [23]. The resultant concentration profiles are shown as dotted lines in Figs. 2 and 3. It can be seen that for $\phi=0.6,1.4$, the initial rate of formation of NO near the flame computed from the equilibrium theory is much smaller than the rates obtained from the detailed kinetic calculations. This discrepancy in rates is confined to the radical overshoot region. Far downstream, the NO formation rates from the detailed calculations and the equilibrium theory are identical.

The results of the detailed kinetic calculations can be extrapolated backward in the same way as the experimental results to compute the prompt NO. The resultant intercept or prompt NO is shown in Fig. 4 which also shows the prompt NO determined experimentally by Bachmaier [5], and by Fenimore [16].
Direct comparison of the results of the detailed kinetic calculations with experimental results is difficult because of differences in initial reactant temperature and in the nitrogen-oxygen ratio. How. ever, it is clear that the detailed calculations, with the kinetics as given in Table 1, fail to reproduce the experimentally observed NO concentrations $[5,13,16]$ for rich flames. In the case of rich flames the computed concentration of NO downstream of the flame is only a few percent of the equilibrium value while the measurements indicate that the concentration of NO rapidly grows to almost the downstream equilibrium value. These results thus support the conclusion of Iverach et al. [13] and Bachmaier [5] that the Zeldovitch Mechanism even with free radical overshoot taken into account cannot explain NO formation downstream of rich hydrocarbon flames.

For near stoichiometric and lean flames the results of the detailed calculations agree qualitatively with the experimental observations of 


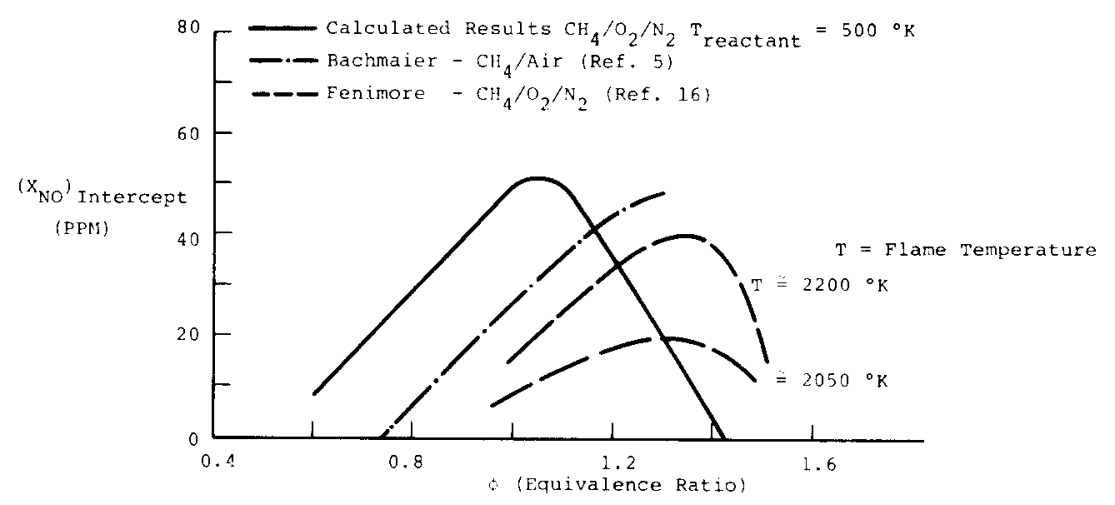

Fig. 4. Comparison of Computed and Measured Prompt NO.

Bachmaier et al. [5]. The spatial variation of NO concentration downstream of propane-air and acetylene-air-flame is shown in Figs. 3 and 4 of [5] over a wide range of equivalence ratios. The decrease in NO formation rate downstream of the flame front for fuel lean methane air flames as shown in Fig. 4 agrees well with trends observed by Bachmaier et al. [5] for lean propane and acetylene air flames. For nearly stoichiometric acetylene air flames with $\phi=0.93,1.09$, and 1.22 , Fig. 4 of [5] shows an initial increase in the rate of NO formation similar to that shown here in Fig. 3 for a stoichiometric flame. The calculated intercept NO concentration shown in Fig. 4 is larger than that measured by Bachmaier [5], and Fenimore [16] for $\phi \leq 1.1$. This discrepancy may be due to the fact that the measurements were made with the unburned fuel at ambient temperature instead of the $500^{\circ} \mathrm{K}$ used in the computations or may also be due to the neglect of transport effects in the model. For rich flames the computed prompt NO concentration is much smaller than experimentally observed values, again suggesting that the Zeldovitch Mechanism fails for rich flames.

A measure of the free radical overshoot can be obtained from the ratio of the maximum mole fraction within the flame to the post flame equilibrium value. This free radical "overshoot ratio" is shown in Fig. 5 for $\mathrm{H}, \mathrm{O}$, and $\mathrm{OH}$ as a function of equivalence ratio for $T_{\text {react }}=500^{\circ} \mathrm{K}$ and $1000^{\circ} \mathrm{K}$. The overshoot ratio of $\mathrm{O}$ and $\mathrm{OH}$ decreases to a minimum near the stoichiometric fuel oxidizer

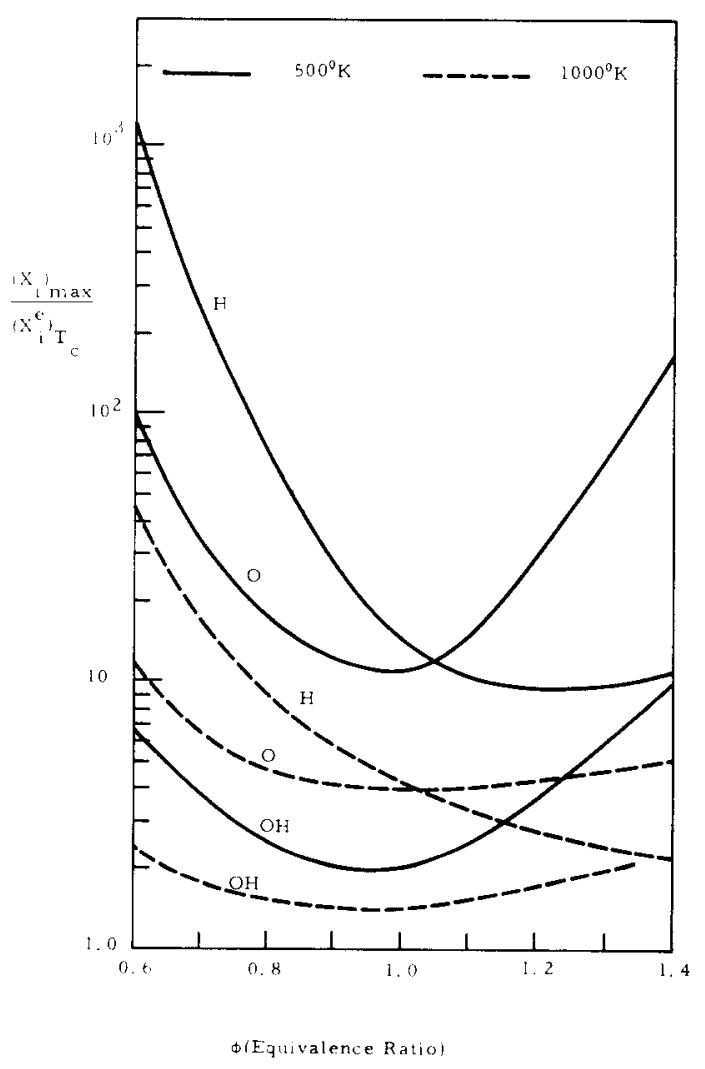

Fig. 5. Radical Overshoot Ratio $\left.\left(X_{i}\right)_{\max } / X_{i} e\right)_{T_{c}}$ vs Equivalence Ratio $\phi$ for $\mathrm{CH}_{4} / \mathrm{O}_{2} / \mathrm{N}_{2}, p=1 \mathrm{~atm}$, $T_{\text {react }}=500^{\circ} \mathrm{K}, 1000^{\circ} \mathrm{K}$ and $\mathrm{N}_{2} / \mathrm{O}_{2}=3.32$.

ratio $(\phi \cong 1)$ and then increases again for rich mixtures, while the overshoot ratio of $\mathrm{H}$ decreases 
monotonically with increasing $\phi$. The NO formation rate, as discussed above, also exceeds the value computed from the equilibrium theory only for rich and lean mixtures.

Figure 5 shows that the radical overshoot decreases with increasing temperature, probably because of a change in the balance between the chain branching and the radical recombination reactions and because of the changes in equilibrium concentrations. This effect can be seen more clearly from Fig. 6 which shows the variation of the overshoot ratio and equilibrium mole fraction of $\mathrm{O}, \mathrm{OH}$, and $\mathrm{H}$ with reactant temperature in the range $500^{\circ} \leq T \leq 1500^{\circ}$ for $\phi=0.6$. Similar curves would be obtained for other values of $\phi$. Extrapolation of these curves indicates that the overshoot ratio, would be even higher at reactant temperatures corresponding to a typical atmospheric ambient temperature of $300^{\circ} \mathrm{K}$. For $T_{\text {react }}$ $=1500^{\circ} \mathrm{K}$ and $\phi=0.6$, where radical overshoot ratios are relatively low, it is found that the rates of NO formation computed from the equilibrium theory and the exact calculations are almost identical in contrast to Fig. 2 for $\phi=0.6$ and $T_{\text {react }}=500^{\circ} \mathrm{K}$. This result lends further support to the "radical overshoot theory" for prompt NO formation, at least for lean flames.

The variation of the radical overshoot ratio with pressure is shown in Fig. 7 for $\phi=0.6$ and $T_{\text {react }}$ $=500{ }^{\circ} \mathrm{K}$ and $1000^{\circ} \mathrm{K}$. It can be seen that the overshoot ratio increases with pressure, with most of this effect in the range $1 \mathrm{~atm}<p<5 \mathrm{~atm}$. The

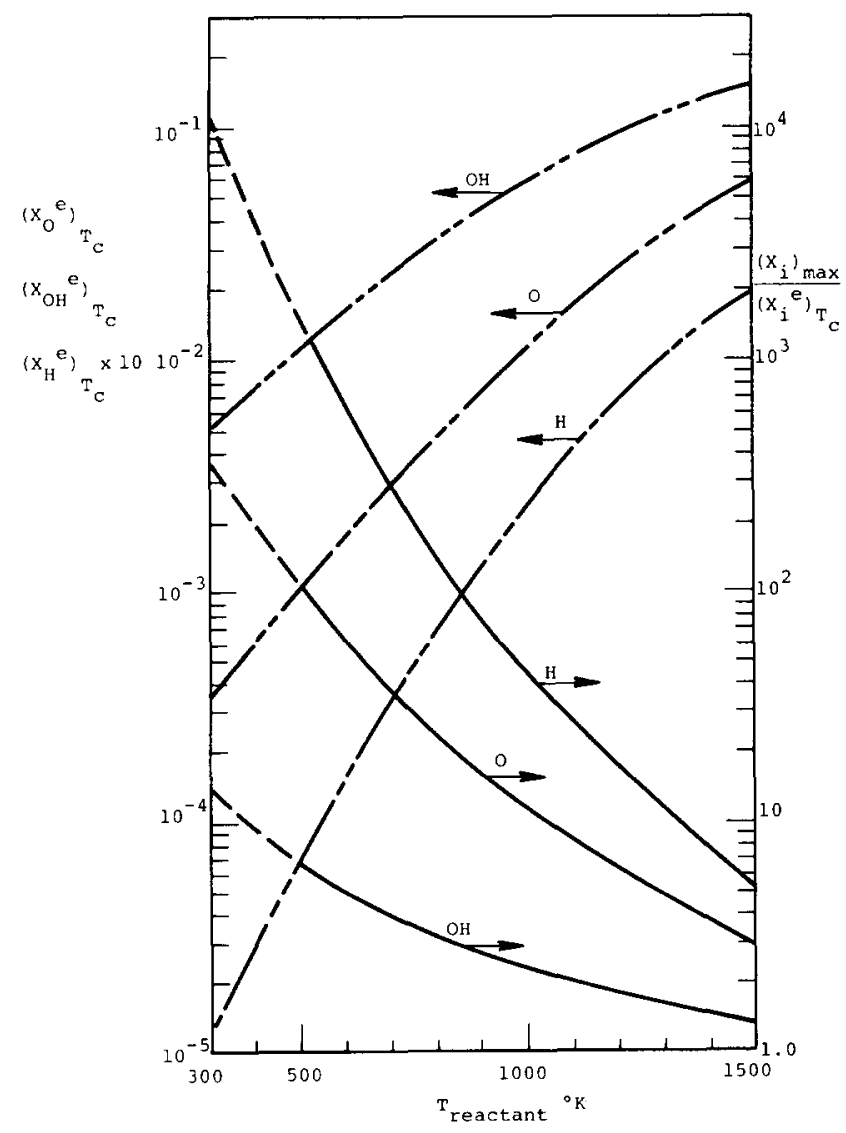

Fig. 6. Radical Overshoot Ratio $\left(X_{i}\right)_{\max } /\left(X_{i} e\right) T_{c}$ and Equilibrium Mole Fraction $\left(X_{i} e\right)_{T_{c}}$ vs Reactant Temperature for $\mathrm{CH}_{4} / \mathrm{O}_{2} / \mathrm{N}_{2}$, $\phi=0.6, p=1 \mathrm{~atm}$, and $\mathrm{N}_{2} / \mathrm{O}_{2}=3.32$. 
increase in flame pressure shifts the radical over shoot ratio to larger values, since a change in the balance between the fast radical branching and slow three-body radical recombination occurs and there is also a change in the equilibrium free radical concentrations. The overshoot ratio decreases with increasing reactant temperatures as noted before.

According to the radical overshoot theory prompt NO results from the high rate of NO formation near the flame due to the high nonequilibrium concentration of the radicals which take part in reactions (XIV) - (XVI). Hence, it is of interest to compare the rate of NO formation immediately downstream of the flame to that com puted using the post flame equilibrium concentration of all species. The ratio of the NO formation rate, $\left(\dot{X}_{\text {NO }}\right)_{\text {kin }}$, near $t=0$, where the nonequilibrium concentration of $O$ is a maximum, to the formation rate $\left(\dot{X}_{\mathrm{NO}}\right)_{\mathrm{eq}}$, computed using the equilibrium theory is shown in Fig. 8 as a function of equivalence ratio for $T_{\text {react }}=500^{\circ} \mathrm{K}$ and $1000^{\circ} \mathrm{K}$. It can be seen that this ratio has a minimum at the same place as the free radical overshoot near $\phi=1.0$, and that the ratio decreases with increasing reactant temperature. Bowman [2] found a similar correlation between prompt NO levels and the overshoot of $\mathrm{O}$ radical concentra. tion for the isothermal combustion of $\mathrm{CH}_{4}-\mathrm{N}_{2}-\mathrm{O}_{2}$ mixtures. The influence of the reactant temperature upon the rate of NO formation is more significant for the rich mixtures.

The variation of the ratio $\left(\dot{X}_{\mathrm{NO}}\right)_{\mathrm{kin}} /\left(\dot{X}_{\mathrm{NO}}\right)_{\mathrm{eq}}$ with pressure is shown in Fig. 9 which also shows $\left(X_{\mathrm{NO}}\right)_{\text {eq }}$. Both the rate ratio and the equilibrium formation rate increase with pressure, a result which is in accord with Fenimore's observation [16] of an increase in intercept NO with increasing pressure.

Recent work [28] indicates that the reactions involving $\mathrm{HO}_{2}$ may have an important influence on radical recombination, and hence on the radical overshoot immediately downstream of the flame. Consequently, several computations have been made in which the kinetics of $\mathrm{CH}_{4}$ combustion have been supplemented by the $\mathrm{HO}_{2}$ reactions and the associated rate constants listed in Table 4.
Calculations were carried out for $\phi=0.6$ and $T_{\text {react }}=500^{\circ} \mathrm{K}, 1000^{\circ} \mathrm{K}$, and for $\phi=1.0$ and $T_{\text {react }}=1000^{\circ} \mathrm{K}$, and for these conditions the inclusion of the $\mathrm{HO}_{2}$ reactions resulted in a decrease of at most 5 percent, 20 percent, and 35 percent in the concentrations of $\mathrm{OH}, \mathrm{O}$, and $\mathrm{H}$, respectively. It is not surprising that the $\mathrm{HO}_{2}$ reactions have the largest effect for the lean mixture and low reactant temperature when free radical concentrations and the radical overshoot ratios are large. For the stoichiometric mixture with $\phi=1.0$ and $T_{\text {react }}=1000^{\circ} \mathrm{K}$, the effect of the $\mathrm{HO}_{2}$ reactions was negligible. The variations of the $\mathrm{O}$ and NO concentrations and the temperature $T$ with time are shown in Fig. 10 for $\phi=0.6$ and $T_{\text {react }}=500^{\circ} \mathrm{K}$ both with and without the $\mathrm{HO}_{2}$ reactions taken into account. During the

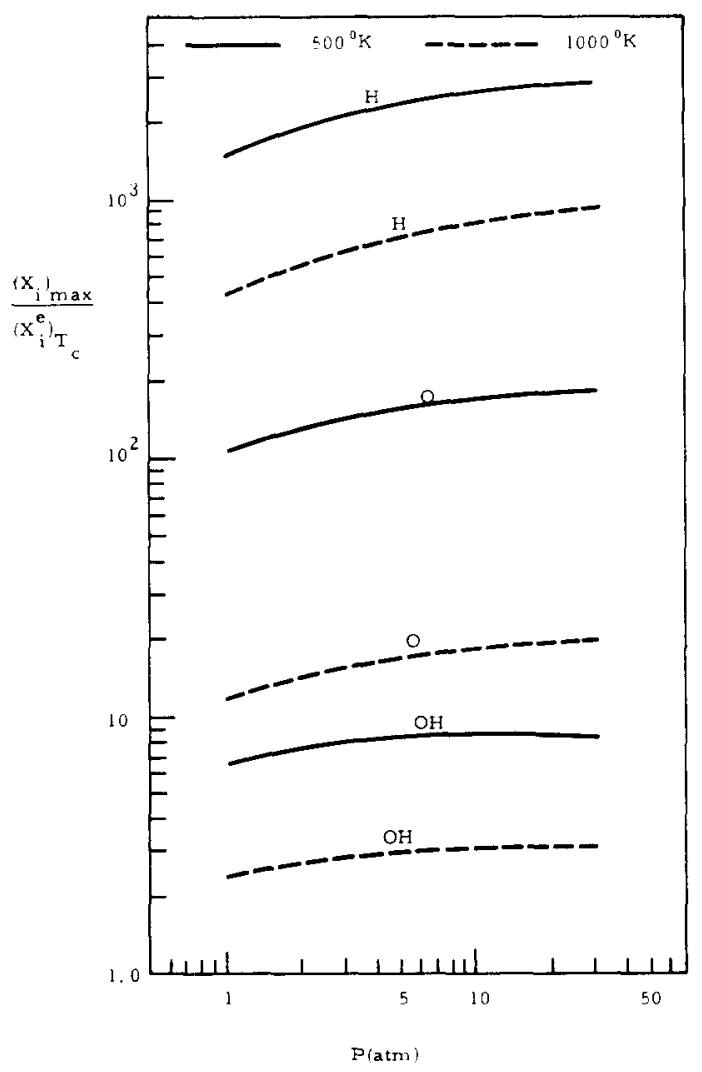

Fig. 7. Radical Overshoot Ratio $\left(X_{i}\right)_{\max } /\left(X_{i} e\right)_{T}$ vs Pressure for $\mathrm{CH}_{4} / \mathrm{O}_{2} / \mathrm{N}_{2}, \phi=0.6, T_{\text {react }}=500{ }^{8} \mathrm{~K}$, and $\mathrm{N}_{2} / \mathrm{O}_{2}=3.32$. 
first millisec after the $O$ concentration peak there is very little change; however, after this initial period the cumulative effect of the $\mathrm{HO}_{2}$ reactions in reducing the free radical concentrations causes an appreciable decrease in the amount of NO which is formed. Thus, while the $\mathrm{HO}_{2}$ reactions appear not to influence the order of magnitude of the NO formation rate, it is important to include these reactions in very precise kinetic computations, particularly in the case of lean flames.

\section{Conclusions}

Detailed kinetic calculations have been used to determine NO formation in methane combustion. The results indicate that in lean and near stoichiometric $\mathrm{CH}_{4}-\mathrm{O}_{2}-\mathrm{N}_{2}$ mixtures "prompt NO", which is related to the very high rates of NO formation in the recombination and post reaction zones, can be explained by the Zeldovitch Mechanism provided the appropriate free radical concentrations are used. For rich mixtures the NO concentrations computed using the detailed kinetics were far below experimentally observed values. The Zeldovitch Mechanism thus fails to explain the production of $\mathrm{NO}$ in the combustion of rich $\mathrm{CH}_{4}-\mathrm{O}_{2}-\mathrm{N}_{2}$ mixtures.
The rate of NO formation close to the combustion zone is influenced by a number of factors including the free radical overshoot and the temperature variation in the recombination region. The radical overshoot is a minimum for mixture ratios near stoichiometric and also decreases with increasing reactant temperatures. The extent of prompt NO, which is related to the discrepancy between NO formation rate determined from the equilibrium theory, and the actual NO formation rate will thus vary considerably with the parameters of the combustion process.

Reactions involving $\mathrm{HO}_{2}$ provide an alternate path for radical recombination and thereby also can influence the production of NO. Comparison in a few cases of results with and without the inclusion of these reactions indicate that, while there is no major change in NO formation, the $\mathrm{HO}_{2}$ reactions can result in an appreciable reduction in the computed NO formation in the case of lean mixtures with a low initial reactant temperature.

Use of the word laminar flame has been avoided in this paper. In a laminar flame diffusion and heat conduction play essential roles and will certainly influence the species profiles through the flame.

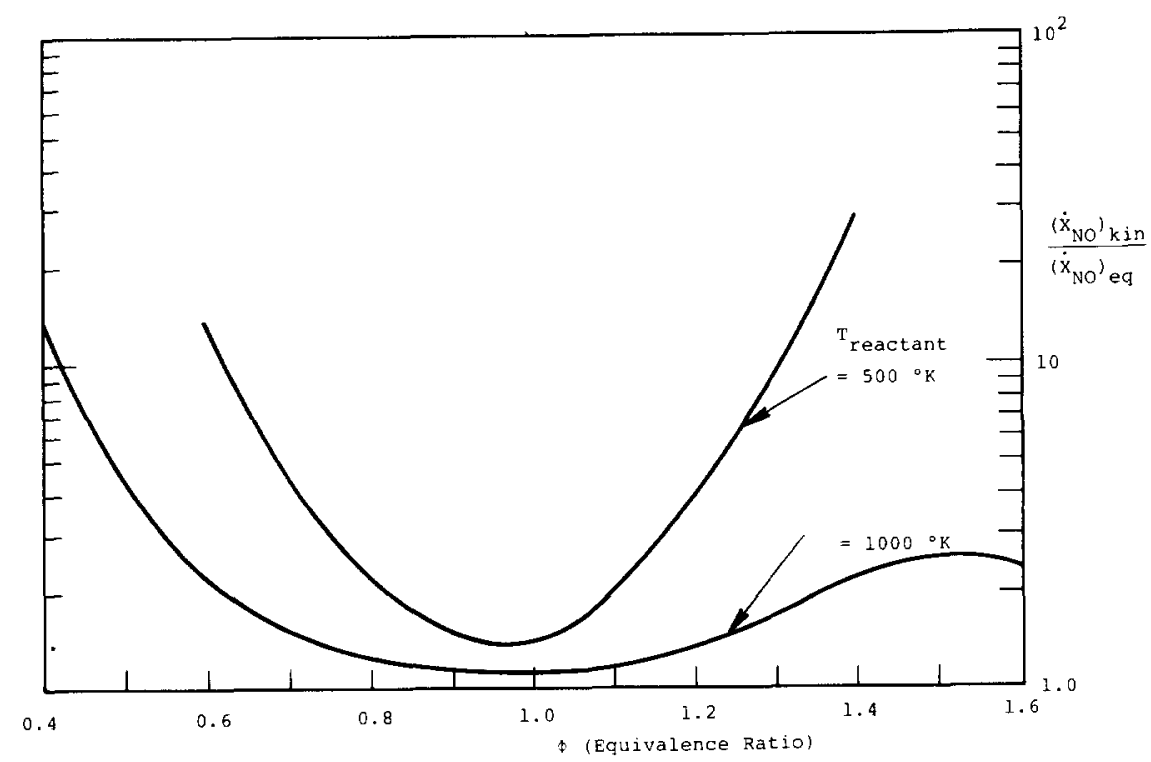

Fig. 8. $\left(\dot{X}_{\mathrm{NO}}\right)_{\mathrm{kin}} /\left(\dot{X}_{\mathrm{NO}}\right)$ eq vs Equivalence Ratio $\phi$ for $\mathrm{CH}_{4} / \mathrm{O}_{2} / \mathrm{N}_{2}$ at $p=1$ atm, $T_{\text {react }}=$ $500^{\circ} \mathrm{K}$ and $1000^{\circ} \mathrm{K}$, and $\mathrm{N}_{2} / \mathrm{O}_{2}=3.32$. 
However, transport effects have been neglected here to simplify the numerical calculations. In many practical combustion systems the combus- tion zone is not a laminar flame. NO formation occurs toward the end and downstream of the combustion zone where gradients, and hence

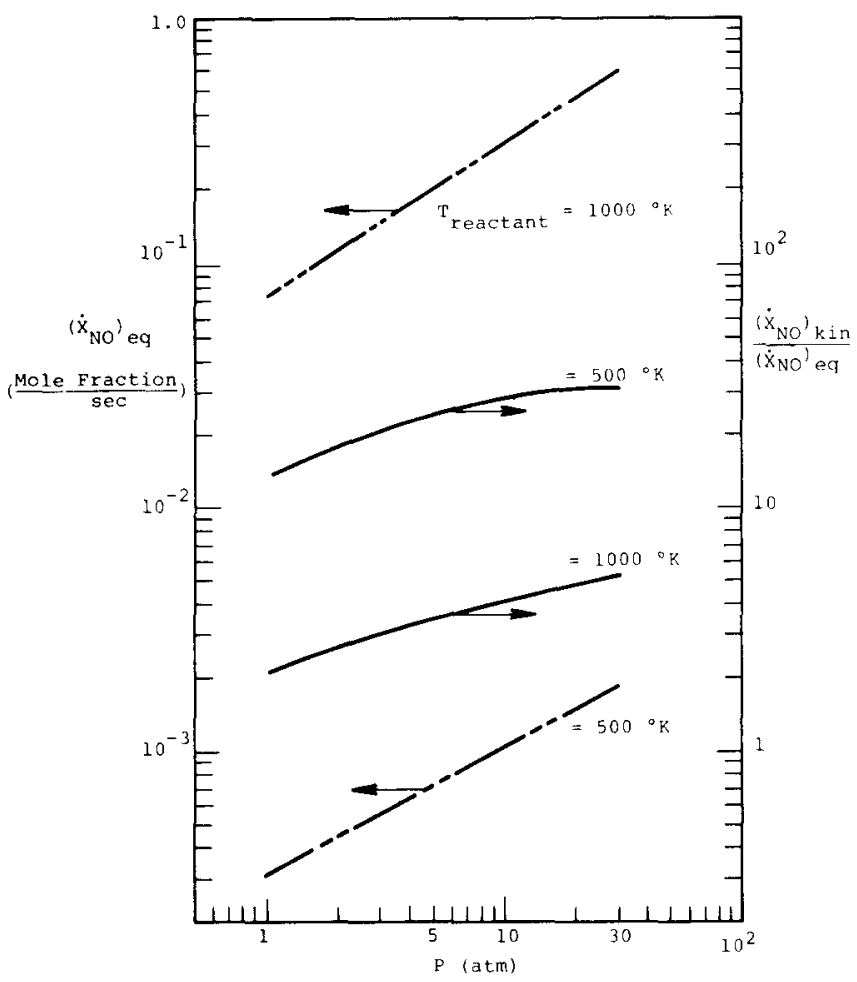

Fig. 9. $\left(\dot{X}_{\mathrm{NO}}\right)_{\mathrm{kin}} /\left(\dot{X}_{\mathrm{NO}}\right)_{\mathrm{eq}}$ and $\left(\dot{X}_{\mathrm{NO}}\right)_{\mathrm{eq}}$ vs Pressure for $\mathrm{CH}_{4} / \mathrm{O}_{2} / \mathrm{N}_{2}$ at $\phi=0.6, T_{\text {react }}=500^{\circ} \mathrm{K}$ and $1000^{\circ} \mathrm{K}$, and $\mathrm{N}_{2} / \mathrm{O}_{2}=3.32$.

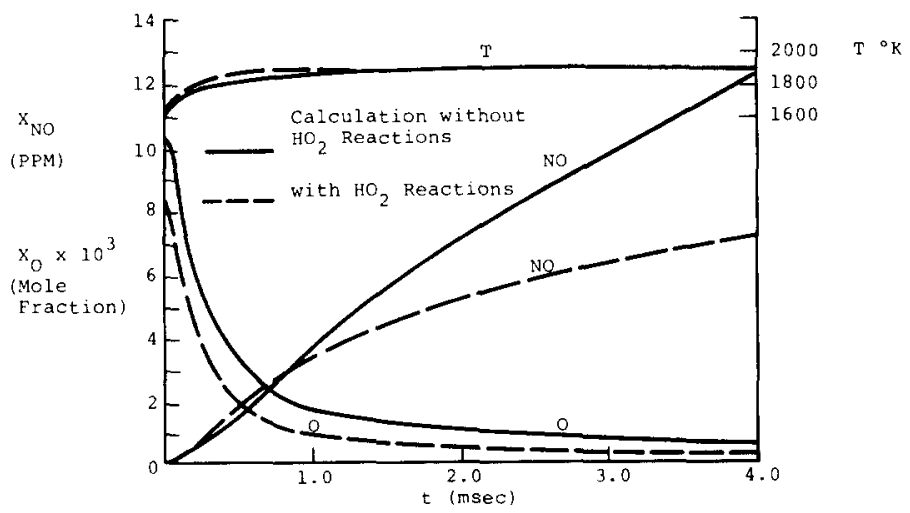

Fig. 10. The Influence of the $\mathrm{HO}_{2}$ Reactions on $\mathrm{O}$, and NO Concentration, and on Temperature; $\phi=0.6, T_{\text {react }}=500^{\circ} \mathrm{K}$. 
Table 4.

$\mathrm{HO}_{2}$ Reactions and Associated Rate Constants

$\begin{array}{rrrl}21 & \mathrm{H}+\mathrm{O}_{2}+\mathrm{M}=\mathrm{HO}_{2}+\mathrm{M} \\ 22 & \mathrm{HO}_{2}+\mathrm{O}=\mathrm{OH}+\mathrm{O}_{2} \\ 23 & \mathrm{HO}_{2}+\mathrm{OH}=\mathrm{H}_{2} \mathrm{O}+\mathrm{O}_{2} \\ 24 & \mathrm{HO}_{2}+\mathrm{H}=\mathrm{H}_{2}+\mathrm{O}_{2} \\ 25 & \mathrm{HO}_{2}+\mathrm{H}=\mathrm{OH}+\mathrm{OH} \\ 26 & \mathrm{HO}_{2}+\mathrm{H}=\mathrm{H}_{2} \mathrm{O}+\mathrm{O} \\ 27 & \mathrm{H}_{2}+\mathrm{HO}_{2}=\mathrm{H}_{2} \mathrm{O}+\mathrm{OH}\end{array}$

\begin{tabular}{|c|c|c|c|c|c|}
\hline \multicolumn{6}{|c|}{ Forward Rate Constant of $\mathrm{HO}_{2}$ Reactions ${ }^{a}$} \\
\hline $\begin{array}{c}j \\
\text { Reaction }\end{array}$ & & $A_{j}$ & $B_{j}$ & $E_{j}$ & Reference \\
\hline 21 & 0.15 & $\times 10^{16}$ & 0 & $-0.500 \times 10^{3}$ & $29^{b}$ \\
\hline 22 & 0.48 & $\times 10^{14}$ & 0 & $0.500 \times 10^{3}$ & 30 \\
\hline 23 & 0.5 & $\times 10^{14}$ & 0 & $0.500 \times 10^{3}$ & 30 \\
\hline 24 & 0.25 & $\times 10^{14}$ & 0 & $0.350 \times 10^{3}$ & 29 \\
\hline 25 & 0.25 & $\times 10^{15}$ & 0 & $0.950 \times 10^{3}$ & 29 \\
\hline 26 & 0.5 & $\times 10^{14}$ & 0 & $0.500 \times 10^{3}$ & 30 \\
\hline 27 & 0.2 & $\times 10^{12}$ & 0 & $0.121 \times 10^{5}$ & 31 \\
\hline
\end{tabular}

$b$ This is the recommended rate constant for He as a collision partner. The rate constant for $\mathrm{N}_{2}$ as a collision partner will be slightly larger but no significant change in the calculated results is expected.

transport effects, are relatively small. The results presented here should therefore provide a reasonable indication of how the detailed kinetics of combustion affect NO formation even though diffusion and heat conduction have been neglected.

The authors would like to express their gratitude to the American Gas Association which provided support for this work under AGA Project BR-26-1, and to Professor J. A. Nicholls, the Project Director, for his many helpful suggestions.

\section{References}

1. Zeldovitch, Ya. B., Sadovnikov, P. Ya., and FrankKamenetski, D. A., Oxidation of Nitrogen in Combustion, Academy of Sci. (USSR), Inst. of Chem. Phys., Moscow-Leningrad (trans. by M. Shlef) (1947).
2. Bowman, C. T., Fourteenth Symposium (International) on Combustion, The Combustion Institute, Pittsburgh, Pa., 729 (1972).

3. Bowman, C. T., and Seery, T. J., Emissions from Continuous Combustion Systems, Plenum Press, 1972, p. 123.

4. Bowman, C. T., Comb. Sci. and Tech. 3, 37 (1971).

5. Bachmaier, F., Eberius, K. H., and Just, Th., Comb. Sci. and Tech. 7, 77 (1973).

6. Heywood, J. B., Gas Turbine Combustor Modeling for Calculating Nitric Oxide Emissions, paper presented at the AIAA/SAE Seventh Propulsion Joint Specialist Conference, Salt Lake City, Utah, June 1971.

7. Craig, R. A., and Pritchard, H. O., Paper presented at the Spring Meeting of the Combustion Institute, Central State Section, Battlesville, Oklahoma, March 1972.

8. Livesey, J. B., Roberts, A. L., and Williams, A., Comb. Sci. and Tech. 4, 9 (1971). 
9. Thompson, D., Brown, T. D., and Beer, J. M., Fourteenth Symposium (International) on Combustion, The Combustion Institute, Pittsburgh, Pa., 787 (1972).

10. Thompson, D., Brown, T. D., and Beer, J. M., Combust. Flame 19, 69 (1972).

11. Sarofim, A. F., Williams, G. C., Lambert, N., and Padia, A., Control of Emission of Nitric Oxide and Carbon Monoxide from Small Scale Combustors, Second Conf. Nat. Gas Res. and Tech., Proc., June 1972.

12. Westenberg, A. A., Comb. Sci. and Tech. 4, 59 (1971).

13. Iverach, D., Basden, K. S., and Kirov, N. Y., Four. teenth Symposium (International) on Combustion, The Combustion Institute, Pittsburgh, Pa., 767 (1972).

14. D'Souza, M. V., and Karim, G. A., Comb. Sci. and Tech. 3, 83 (1971).

15. Williams, G. C., Hottel, H. C., and Morgan, A. C., Twelfth Symposium (International) on Combustion, The Combustion Institute, Pittsburgh, Pa., 913 (1968).

16. Fenimore, C. P., Thirteenth Symposium (International) on Combustion. The Combustion Institute, Pittsburgh, Pa., 373 (1970).

17. Marteney, P. J., Comb. Sci. and Tech. 1, 461 (1970).

18. JANAF Thermodynamic Tables, The Thermal Research Lab., Dow Chemical Co., June 1971.

19. Gordon, S., and McBride, S., NASA SP-273, Lewis Research Center, Cleveland, Ohio (1971).

20. Bowen, S. W., AMPLCT, a Numerical Integration Routine for Systems of Stiff Differential Equations, The Univ. of Mich., ORA Report 033390-2-T, June 1971.

21. Gear, C. W., Comm. $A C M$ 14, 176 (1971).

22. Gear, C. W., Comm. ACM 14, 185 (1971).
23. Ay, J. H., Ion and Nitric Oxide Formation in Combustion: Examples of Trace Species in Flames, Thesis, The Univ. of Mich., Ann Arbor, Mich., 1974.

24. Nicholls, J. A., Sichel, M., Mason, C. J., Garrison, R. P., Geister, D. E., Liang, H. C., and Paul, J., Combustion Dynamics as Related to Air Pollution, The Univ. of Mich., Report UM-320057-2-P, prepared under AGA Project BR-26-1, Sept., 1972.

25. Nicholls, J. A., Sichel, M., Ay, J. H., Geister, D. E., and Liang, H. C., Combustion Dynamics as Related to Air Pollution, The Univ. of Mich., Report UM 320057-3-P, prepared under AGA Project BR-26-1, Sept., 1973.

26. Sarofim, A. F., and Pohl, J. H., Fourteenth Symposium (International) on Combustion, The Combustion Institute, Pittsburgh, Pa., 739 (1972)

27. Haynes, B. S., Iverach, D., and Kirov, N. Y., Fifteenth Symposium (International) on Combustion (in print), The Combustion Insitute, Pittsburgh, Pa. (1974).

28. Homer, J. B., and Sutton, M. M., Combust. Flame 20, 71 (1973).

29. Baulch, D. L., Drysdale, D. D., Horne, D. G., Lloyd, A. C., Evaluated Kinetic Data for High Temperature Reactions, CRC Press, Cleveland, Ohio.

30. Lloyd, A. C., Evaluated and Estimated Data for the Gas Phase Reactions of the Hydroperoxy Radical, NBS Report 10447, 1973.

31. Voevodsky, V. V., Seventh Symposium (International) on Combustion, Butterworths (1959).

32. Jenkins, D. R., Yumlu, V. S., and Spalding, D. B., Eleventh Symposium (International) on Combustion, The Combustion Institute, Pittsburgh, Pa., 799 (1966)

Received 20 December 1974; revised 4 August 1975 